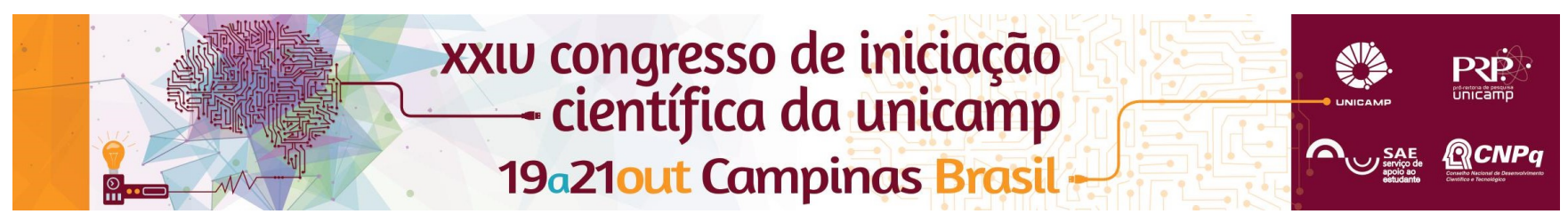

\title{
Síntese de Híbridos Moleculares Derivados de Acil-Hidrazonas Candidatos a Fármacos para Doença de Alzheimer
}

\author{
Isabela P. Koury*, Wanda P. Almeida.
}

\section{Resumo}

A doença de Alzheimer está cada vez mais prevalente na sociedade e com isso há o aumento da preocupação em encontrar fármacos mais potentes e com menores efeitos adversos. Como uma das hipóteses da doença de Alzheimer é o déficit colinérgico, no qual a transmissão colinérgica é diminuída, um dos alvos de fármacos é a enzima acetilcolisterase (AChE). Essa enzima tem como função principal a degradação do neurotransmissor acetilcolina. Portanto, ao inibir a AChE, espera-se que a atividade colinérgica seja prolongada, retardando o avanço da doença. Neste trabalho, sintetizamos e caracterizamos uma série de acil-hidrazonas derivadas da isoniazida para serem investigadas como inibidores da AChE.

\section{Palavras-chave:}

Alzheimer, Acil-hidrazonas, Acetilcolinesterase.

\section{Introdução}

A doença de Alzheimer (DA) vem se tornando um grande desafio na saúde pública de todo o mundo, já que o indivíduo apresenta deficiência de suas atividades cognitivas dificultando diversos aspectos comuns de sua vivência. Além disso, é sabido que a DA é a principal causa de demência em idosos, alcançando $55,1 \%$ dos casos, sendo que a maioria são em mulheres, pessoas de cor branca e de classe social $\mathrm{C}$ e $\mathrm{D}$. Apesar dos inúmeros estudos, a causa da DA permanece desconhecida, existindo hipóteses sobre o que pode levar a desencadear essa doença. Baseados na hipótese colinérgica, a descoberta por substâncias capazes de melhorar o déficit colinérgico é uma importante área na pesquisa de fármacos para tratar a Doença de Alzheimer. Atualmente, os inibidores de aceticolinesterase (AChE) são os principais fármacos que fazem parte do arsenal terapêutico para a DA. ${ }^{1}$ A função acil-hidrazona é conhecida como uma subestrutura privilegiada, quer seja pela possibilidade de interagir via ligação de hidrogênio com resíduos de aminoácidos situados em sítio catalítico de enzimas ou sítios ligantes de receptores, ou como espaçadores, posicionando adequadamente grupos complementares. ${ }^{2}$ Neste trabalho, sintetizamos e caracterizamos 12 acilhidrazonas inéditas, derivadas da isoniazida.

\section{Resultados e Discussão}

As acil-hidrazonas foram sintetizadas por uma reação de acoplamento entre o grupo amino da função hidrazida e a carbonila do aldeído, refluxando os reagentes em etanol (Fig. 1). As acil-hidrazonas alvo foram obtidas em rendimentos variando de 65 a $90 \%$.

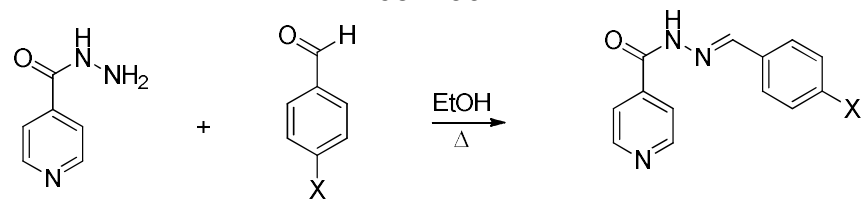

Figura 1: Formação de acilidrazonas a partir da isoniazida.

Para comprovação das estruturas químicas sintetizadas, foi feita pela análise dos espectros de infra-vermelho e Ressonância Magnética Nuclear (RMN) de hidrogênio e carbono. A configuração da ligação dupla foi assinalada como sendo E. A Fig. 2 apresenta a estrutura de um dos compostos sintetizados, evidenciando a ligação dupla $E$.

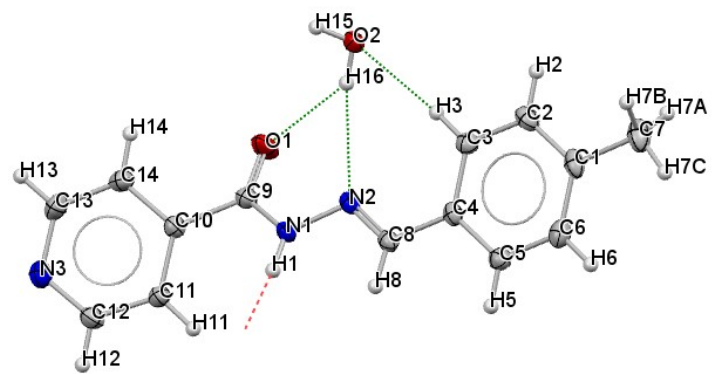

Figura 2. Estrutura molecular de uma das acil-hidrazonas sintetizadas, apresentando uma molécula de $\mathrm{H}_{2} \mathrm{O}$ em ligação de hidrogênio. ${ }^{3}$

O efeito de algumas acil-hidrazonas sobre a atividade da AChE foi avaliado pelo método de Ellman, adaptado, em microplaca. Porém, os resultados preliminares não foram satisfatórios (inibição 50\%), nos incentivando a realizar modificações estruturais para otimizar o efeito inibitório.

\section{Conclusões}

Nesse trabalho foram sintetizadas e caracterizadas 12 acilhidrazonas a partir da hidrazida do ácido isonicotínico. Em relação ao efeito sobre a AChE, é necessário fazer algumas modificações estruturais para otimizar o efeito inibitório.

\section{Agradecimentos}

Agradecimento ao LAFAME por ter me acolhido durante o período da pesquisa e até mesmo após ele. Agradecimento ao CNPq-PIBIC pela oportunidade. Fapesp 2013/18203-5 pelo financiamento.

1Janus e Westaway. Physiol. Behav., 2001, 73, 873, e referências citadas; ${ }^{2}$.Fraga, Tesch e Maia. Exp. Opin. Ther. Pat., 2014, 11, 1161.

${ }^{3}$ Koury, Almeida e Simoni. Acta Cryst. E, 2016, 1, x160752. 